controls. Abnormal NE grade is best predicted by day 2 serum Epo and IL-8 while CSF levels were not predictive of outcome. Serum biomarkers may have a role in long term outcome prediction following NE.

\section{PS-158 EMERGENCY TRIAGE ASSESSMENT AND TREATMENT (ETAT) TRAINING IN A SEMIRURAL HOSPITAL IN SIERRA LEONE - RETENTION OF KNOWLEDGE AND FEED BACK}

${ }^{1}$ A Lewis, ${ }^{1} \mathrm{~L}$ Sendell, ${ }^{1} \mathrm{~T}$ Hildebrandt, ${ }^{2} \mathrm{M}$ Bryant. ${ }^{1}$ Paediatrics, Princess of Wales Hospital, Bridgend, UK; ${ }^{2}$ General Practice, ABMU Health Board, Swansea, UK

\subsection{6/archdischild-2014-307384.454}

Background and aims ETAT is a well established training course initiated through WHO in 2005. It is aimed at resource poor countries and teaches triage of children leading to effective emergency treatment. The course is run over 3 days consisting of tutorials and practical skill stations. We delivered ETAT for the first time in a semirural hospital situated in Lunsar, Sierra Leone.

Methods 20 candidates participated in the course. Candidates were asked to complete a test consisting of 25 points and to give structured feed back after completion of all modules.

Results 20 initial post course assessments were performed with an average score of $78.2 \%$. overall feedback was very good with all categories rated as excellent or good. Overriding themes were:

"The training should be repeated on a regular basis"

"Tutorials and practical skill stations will help me to implement this knowledge into practice".

Conclusions ETAT training is well received with all feedback categories rated as either excellent or good. The initial testing demonstrated good knowledge of topics taught with an overall score of $78.2 \%$. Post course retention of knowledge however is likely to be poor in line with previously published data. To achieve long term retention of knowledge ETAT training should be delivered repeatedly, ideally led by the local team.

\section{PS-159 BETA-AMYLOID AND S100B COULD BE VALUABLE BIOMARKERS AFTER NEONATAL HYPOXIA-REOXYGENATION. A STUDY IN NEWBORN PIGS}

${ }^{1} \mathrm{~T}$ Benterud, ${ }^{1} \mathrm{~L}$ Pankratov, ${ }^{1} \mathrm{R}$ Solberg, ${ }^{1} \mathrm{OD}$ Saugstad, ${ }^{2} \mathrm{~A}$ Skinningsrud, ${ }^{3} \mathrm{~N}$ Bolstad. ${ }^{1}$ Department of Pediatric Research, Oslo University Hospital, Oslo, Norway; ${ }^{2}$ Department of Medical Biochemistry, Akershus University Hospital, Oslo, Norway; ${ }^{3}$ Department of Medical Biochemistry, Oslo University Hospital, Oslo, Norway

\subsection{6/archdischild-2014-307384.455}

Background and aims The use of biomarkers is an important strategy for risk stratification for neonates admitted to the NICU after perinatal asphyxia. Total Tau (t-Tau), phosphorylatedTau (pTau) and Beta-Amyloid (1-42) (b-A) in CSF, are useful biomarkers in various neurological disorders, such as Alzheimer's. Few, if any, experiments have investigated the possible association between oxidative stress in the neonates and the levels of these proteins.

\section{Abstract PS-159 Table 1}

\begin{tabular}{|l|l|l|l|l|l|}
\hline \multicolumn{1}{|c|}{ CSF } & Severe Hypox & $P$-Value & Mod.Hypox & $P$-Value & Control \\
\hline S100B ng/ml & $40(36)$ & $<0.01$ & $39(39)$ & $<0.05$ & $12(9)$ \\
\hline$\beta-A ~ p g / m l$ & $1002(401)$ & 0.01 & $1076(206)$ & $<0.05$ & $1290(143)$ \\
\hline p-Tau pg/ml & $85(49)$ & n.s. & $95(64)$ & n.s. & $68(15)$ \\
\hline
\end{tabular}

\section{Abstract PS-159 Table 2}

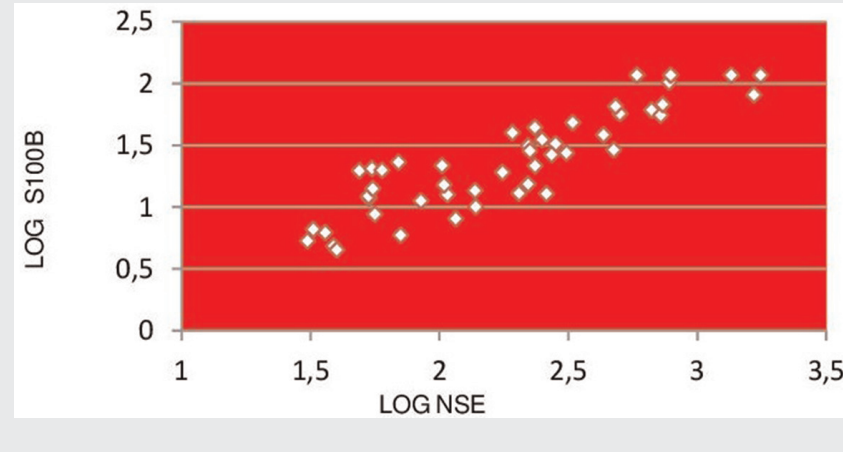

Objective To study any correlations between the levels of $\mathrm{t}$-Tau, $\mathrm{p}$ Tau, b-A, S100B and NSE and oxidative stress in the newborn pig. Methods Fifty-four newborn piglets, age12-36 h, were included. One control group $(n=6)$ and 2 experimental groups $(n=24)$, exposed to global hypoxia $(8 \% \mathrm{O} 2)$ until $\mathrm{BE}$ reached $-15 \mathrm{mmol} / \mathrm{l}$ (moderate hypoxia) or $-20 \mathrm{mmol} / \mathrm{l}$ (severe hypoxia) or BP fell below $20 \mathrm{mmHg}$. The pigs were observed for $9.5 \mathrm{~h}$. CSF was collected $9.5 \mathrm{~h}$ after the intervention.

Results

Discussion To our knowledge this is the first study investigating the levels of Tau, p-Tau and b-Amyloid in a neonatal animal model after hypoxia-reoxygenation. The reduced level of CSF bAmyloid may reflect the death of neurons after neonatal hypoxia. A strategy of measuring several biomarkers should be applied when assessing the prognosisafter perinatal asphyxia.

Conclusion These findings show that b-amyloid and S100b are significantly changed in neonatal pigs subjected to hypoxia compared to controls, thus they may be valuable biomarkers after perinatal asphyxia.

\section{Long Term Follow Up}

\section{PS-160 VOLUME OF CEREBELLUM AND THALAMUS IS ASSOCIATED WITH WORKING MEMORY PERFORMANCE IN CHILDREN AND ADOLESCENTS BORN VERY PRETERM}

${ }^{1}$ F Wehrle, ${ }^{2} \mathrm{~A}$ Buchmann, ${ }^{3} \mathrm{~A}$ Hüsser, ${ }^{4} \mathrm{~B}$ Latal, ${ }^{4} \mathrm{R}$ Huber, ${ }^{5} \mathrm{R}$ O'Gorman, ${ }^{6} \mathrm{~L}$ Kaufmann, ${ }^{5} \mathrm{H}$ Speckbacher, ${ }^{3} \mathrm{C}$ Verrey, ${ }^{1} \mathrm{C}$ Hagmann. ${ }^{1}$ Division of Neonatology, University Hospital of Zurich, Zurich, Switzerland; '2Department of Neurology, University Hospital of Zurich, Zurich, Switzerland; ${ }^{3}$ Department of Psychology, University of Zurich, Zurich, Switzerland; ${ }^{4}$ Child Development Center, University Children's Hospital, Zurich, Switzerland; ${ }^{5}$ Center for MR Research, University Children's Hospital, Zurich, Switzerland; ${ }^{6}$ Department of Psychiatry and Psychotherapy A, General Hospital, Hall in Tyrol, Austria

\subsection{6/archdischild-2014-307384.456}

Background Children and adolescents born very preterm (VPT) are at increased risk for altered brain development [1] and impaired cognitive performance [2]. Decreased regional brain volume in VPT infants has been associated with later working memory deficits [3]. This study aims to identify associations between regional brain volume and working memory performance in VPT children.

Design/methods Thirty-three VPT children between 10 and 16 and 34 term-born peers were examined. Three-dimensional T1and T2-weighted MR images were acquired on a 3T GE scanner. Regional brain volumes were calculated using FreeSurfer 5.3.0. Working memory was assessed using the spatial working memory (SWM) task of the Cantab test battery. 